\title{
Возможность расчёта содержания попутных компонентов в минералах хибинских апатито-нефелиновых руд по данным рядового опробования
}

\author{
Коноплёва Н.Г. ${ }^{1}$, Калашников А.О. ${ }^{1,2}$, Иванюк Г.Ю. ${ }^{1,2}$ \\ ${ }^{1}$ Центр наноматериаловедения КНЦ РАН, Anamumbl, konoplyova55@mail.ru \\ ${ }^{2}$ Геологический институт КНЦ РАН, Anamumbl, geoksc@geoksc.apatity.ru
}

Аннотация. В статье показана принципиальная возможность определения содержания попутных компонентов в апатите, нефелине, титаните и магнетите по результатам рядового опробования пород и руд хибинских месторождений. Предлагаемая методика может существенно упростить подсчёт запасов попутных компонентов в апатито-нефелиновых рудах.

Ключевые слова: попутные полезные ископаемые, апатито-нефелиновые руды, апатит, нефелин, титанит, магнетит.

\section{Possibility of calculation of trace elements concentrations in minerals of the Khibiny apatite-nepheline ores according to ordinary sampling}

\author{
Konopleva N.G. ${ }^{1}$, Kalashnikov A.O. ${ }^{1,2}$, Ivanyuk G.Yu. ${ }^{1,2}$ \\ ${ }^{1}$ Nanomaterials Research Centre KSCRAS, Apatity, konoplyova55@mail.ru \\ ${ }^{2}$ Geological institute KSC RAS, Apatity,geoksc@geoksc.apatity.ru
}

\begin{abstract}
The article shows the possibility of calculation of trace elements concentrations in apatite, nepheline, titanite and magnetite, according to ordinary sampling of apatite-nepheline ores. The offered procedure can essentially simplify the estimation of reserves of trace elements in apatite-nepheline ores.
\end{abstract}

Key words: trace elements, apatite-nepheline ores, apatite, nepheline, titanite, magnetite.

В балансе запасов апатит-нефелиновых руд хибинских месторождений помимо основного компонента $\mathrm{P}_{2} \mathrm{O}_{5}$ учтены запасы попутных полезных ископаемых II группы (нефелина, титанита и титаномагнетита) и III группы ( $\mathrm{SrO}, \mathrm{REE}_{2} \mathrm{O}_{3}$ и $\mathrm{F}$ в апатите; $\mathrm{Al}_{2} \mathrm{O}_{3}, \mathrm{Ga}_{2} \mathrm{O}_{3}, \mathrm{Rb}_{2} \mathrm{O}$ и $\mathrm{Cs}_{2} \mathrm{O}$ в нефелине; $\mathrm{TiO}_{2}$ и $\mathrm{Nb}_{2} \mathrm{O}_{5}$ в сфене; $\mathrm{Fe}_{\text {обш }}$ и $\mathrm{TiO}_{2}$ в титаномагнетите). Рядовое опробование керна разведочных скважин включает в себя определение содержаний $\mathrm{P}_{2} \mathrm{O}_{5}, \mathrm{Al}_{2} \mathrm{O}_{\text {зобщ. }}, \mathrm{Al}_{2} \mathrm{O}_{\text {зк.р }}$. (кислотно-растворимого) и $\mathrm{TiO}_{2}$ Такой набор компонентов позволяет достаточно уверенно оценить количество основных минералов в породах продуктивной толщи. Содержание апатита связано прямой функциональной зависимостью с содержанием $\mathrm{P}_{2} \mathrm{O}_{5}\left(\mathrm{C}_{\mathrm{Ap}}=2.451 \times \mathrm{C}_{\mathrm{P} 205}\right)$. Основными минералами-концентраторами алюминия в продуктивной зоне месторождений являются нефелин (87-97 \%) и полевой шпат (1-11\%) $\mathrm{Al}_{2} \mathrm{O}_{\text {зобщ. }}$ Содержание $\mathrm{Al}_{2} \mathrm{O}_{\text {зк.р. }}$ позволяет оценивать содержание нефелина в породах. Соответственно, разность $\mathrm{Al}_{2} \mathrm{O}_{\text {зобщ. }}$ и $\mathrm{Al}_{2} \mathrm{O}_{\text {3к.р. }}\left(\Delta \mathrm{Al}_{2} \mathrm{O}_{3}\right)$ характеризует степень полевошпатовости пород. Диоксид титана концентрируется, главным образом, в титаните (59-86 \%) и титаномагнетите (4-30 \%).

Методика подсчёта запасов минералов в апатит-нефелиновых рудах по уравнениям регрессии от компонентов рядового опробования давно вошла в практику работы Мурманской ГРЭ и АО «Апатит». Но природные связи в минеральной системе Хибинского массива гораздо глубже. Как показали наши комплексные геолого-минералогические исследования, изменение состава минералов в пределах Хибинского массива происходит закономерно и взаимосогласованно (Иванюк и др., 2009). Учитывая это качество минеральной системы, мы сделали попытку оценить изменение состава промышленно-ценных минералов в зависимости от состава пород по основным компонентам рядового опробования.

Для выполнения работы использованы результаты анализов монофракций минералов и рядового опробования, приведённые в отчётах по детальной разведке хибинских месторождений. 


\section{Попутные компоненты в аnamume}

В хибинском апатите реализуются две основные схемы изоморфных замещений:

$$
\text { 1) } \mathrm{REE}^{3+}+\mathrm{Si}^{4+} \leftrightarrow(\mathrm{Ca}, \mathrm{Sr})^{2+}+\mathrm{P}^{5+} ; \quad \text { 2) } \mathrm{Na}^{+}+\mathrm{REE}^{3+} \leftrightarrow 2(\mathrm{Ca}, \mathrm{Sr})^{2+}
$$

Обе они отвечают за изменение состава апатита при переходе от вмещающих пород к апатитнефелиновым рудам, т.е. возрастание количества апатита $\left(\mathrm{P}_{2} \mathrm{O}_{5}\right)$ в ийолит-уртитах и апатитонефелиновых рудах сопровождается его очищением от примесных $\mathrm{Na}$, REE и $\mathrm{Si}$ в пользу $\mathrm{Ca}, \mathrm{Sr}$ и $\mathrm{P}$. В отношении Са и $\mathrm{Sr}$ проявлена специализация, соответственно, мелких и крупных месторождений: на крупных месторождениях (Кукисвумчорр-Юкспор, Расвумчорр, Коашва) очищение апатита от $\mathrm{REE}$ и Si сопровождается увеличением содержания $\mathrm{Ca}$, а на мелких - Sr. Поэтому, чем богаче руда (выше содержание $\mathrm{P}_{2} \mathrm{O}_{5}$ ) и крупнее месторождение, тем меньше стронция в составе апатита (Коноплёва и др., 2013).

Ещё в 1985 году при изучении апатита из руд месторождений Олений Ручей и Коашва был установлен закономерный характер изменения количества изоморфных примесей $\mathrm{SrO}, \mathrm{REE}_{2} \mathrm{O}_{3}$ и $\mathrm{F}$ в апатите от содержания $\mathrm{P}_{2} \mathrm{O}_{5}$ в руде (Иванов, 1987). Тогда же было сделано предположение, что существует единая закономерная связь компонентов в составе апатита, характерная для всех месторождений Юго-восточного рудного поля, а возможно и для всех хибинских апатитовых месторождений. Графики, приведённые на рисунке 1 показывают, что это предположение оказалось верным.

Общее количество $R E E_{2} \mathrm{O}_{3}$ и $\mathrm{SrO}$ в апатите увеличивается при возрастании доли ийолитуртитов в массе руды (обратно пропорционально содержанию апатита), так что переход к добыче всё более бедных руд на всё более глубоких горизонтах может сопровождаться увеличением содержания этих компонентов в апатитовом концентрате.
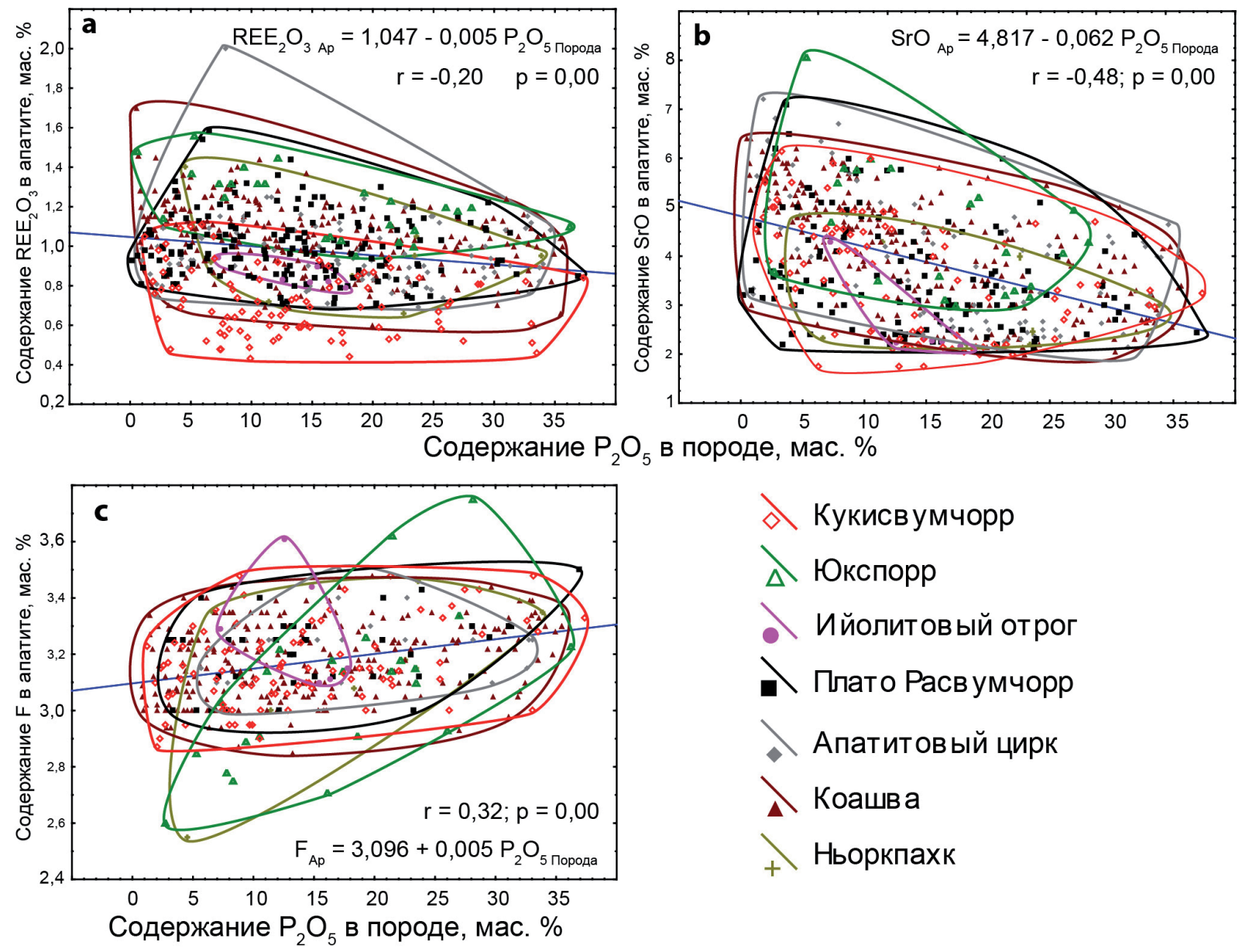

$\diamond$ Кукисвумчорр

$\triangle$ Юкспорр

Ийолитовый отрог

- Плато Расвумчорр

Апатитовый цирк

Коашва

Ньоркпахк

Рис. 1. Зависимость содержаний $\mathrm{REE}_{2} \mathrm{O}_{3}(\mathrm{a}), \mathrm{SrO}(\mathrm{b})$ и $\mathrm{F}(\mathrm{c})$ в апатите от содержания $\mathrm{P}_{2} \mathrm{O}_{5}$ в породе.

Fig. 1. $\mathrm{REE}_{2} \mathrm{O}_{3}(\mathrm{a}), \mathrm{SrO}(\mathrm{b})$ and $\mathrm{F}(\mathrm{c})$ concentrations in apatite $v s . \mathrm{P}_{2} \mathrm{O}_{5}$ contents in the rock. 

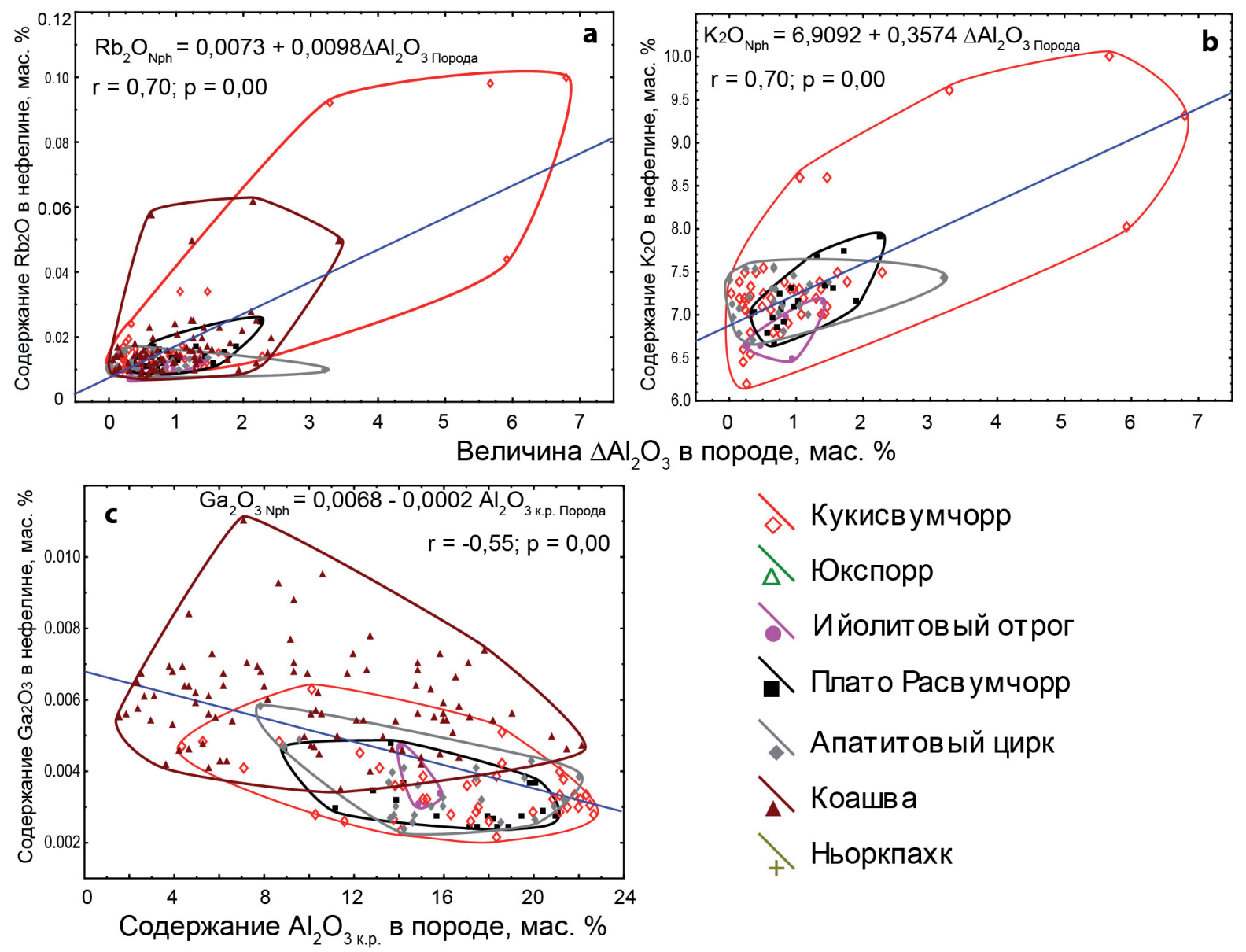

\section{$\diamond$ Кукисвумчорр \\ $\triangle$ Юкспорр}

Ийолитовый отрог

Плато Расв умчорр

Апатитовый цирк

Коашва

Ньоркпахк

Рис. 2. Зависимости содержаний $\mathrm{Rb}_{2} \mathrm{O}(\mathrm{a})$ и $\mathrm{K}_{2} \mathrm{O}(\mathrm{b})$ в нефелине от величины $\Delta \mathrm{Al}_{2} \mathrm{O}_{3}$ в породе и $\mathrm{Ga}_{2} \mathrm{O}_{3}$ в нефелине от содержания $\mathrm{Al}_{2} \mathrm{O}_{3 \text { к.р. }}$ в породе.

Fig. 2. $\mathrm{Rb}_{2} \mathrm{O}$ (a) and $\mathrm{K}_{2} \mathrm{O}$ (b) concentrations in nepheline vs. $\Delta \mathrm{Al}_{2} \mathrm{O}_{3}$ contents in the rock and $\mathrm{Ga}_{2} \mathrm{O}_{3}$ concentrations (c) in nepheline vs. $\mathrm{Al}_{2} \mathrm{O}_{3 \text { a.s. }}$ contents in the rock.

Концентрация фтора в апатите связана прямо пропорциональной зависимостью с содержанием $\mathrm{P}_{2} \mathrm{O}_{5}$ (апатита) в породе: чем беднее руда, тем меньше фтора в составе апатита.

\section{Попутные компоненты в нефелине}

Вторым по значимости и востребованности промышленно ценным минералом является нефелин, концентрирующий в себе $\mathrm{Al}_{2} \mathrm{O}_{3}, \mathrm{Ga}_{2} \mathrm{O}_{3}, \mathrm{Rb}_{2} \mathrm{O}$ и $\mathrm{Cs}_{2} \mathrm{O}$. Содержание алюминия в нефелине определяется изоморфизмом по известной схеме:

$$
\square_{B}+\mathrm{Si}_{T}^{4+} \rightarrow \square_{A}+\mathrm{K}_{B}^{+}+(\mathrm{Al}, \mathrm{Fe})^{3+}{ }_{T},-
$$

сопровождающей уменьшение температуры кристаллизации минерала (Яковенчук и др., 2010). Это означает, что в наиболее поздних фоидолитах и апатит-нефелиновых рудах нефелин содержит повышенное относительно вмещающих нефелиновых сиенитов количество алюминия и калия (а также $\mathrm{Ga}$ и $\mathrm{Rb}$, которые скоррелированы с калием [ $r=0.21$ и $r=0.8$ соответственно], и $\mathrm{Cs})$.

При изучении нефелина из пород месторождений Олений Ручей и Коашва была выявлена высоко значимая положительная корреляционная зависимость между содержанием рубидия в нефелине и количеством полевого шпата в породе (Иванов, 1987). На рисунке 2 показаны зависимости содержаний $\mathrm{Rb}_{2} \mathrm{O}$ (рис. $2 \mathrm{a}$ ) и $\mathrm{K}_{2} \mathrm{O}$ (рис. 2 b) в нефелине от величины $\Delta \mathrm{Al}_{2} \mathrm{O}_{3}$ в породе Положительная корреляция этих параметров показывает, что вовлечение в отработку бедных руд с высоким содержанием полевошпатсодержащих ийолит-уртитов приведёт к увеличению содержания $\mathrm{Rb}_{2} \mathrm{O}$ и $\mathrm{K}_{2} \mathrm{O}$ в составе нефелинового концентрата. 
Для оценки содержания галлия в нефелине можно использовать его связь с содержанием $\mathrm{Al}_{2} \mathrm{O}_{3 \text { к.p. }}$ (нефелина) (рис. 2 c). Сложнее обстоит дело с оценкой содержания $\mathrm{Cs}_{2} \mathrm{O}$ в нефелине. При обработке имеющегося массива данных по составу нефелина удалось установить значимую корреляционную связь содержания $\mathrm{Cs}_{2} \mathrm{O}$ только с содержанием $\mathrm{Rb}_{2} \mathrm{O}$ в нефелине $(r=0.71)$.

\section{Попутные компоненты в титаните}

Изменение состава хибинского титанита при переходе от нефелиновых сиенитов к фоидолитам и апатито-нефелиновым породам определяется изоморфизмом по сложной схеме:

$$
\mathrm{Ca}^{2+} \mathrm{REE}^{3+}+2 \mathrm{Zr}^{4+}+2 \mathrm{Al}^{3+} \rightarrow 2 \mathrm{~K}^{+}+\mathrm{Ti}^{4+} \mathrm{Nb}^{5+}+2 \mathrm{Si}^{4+} .
$$

В результате, титанит апатито-нефелиновых руд и ийолит-уртитов оказывается заметно обогащённым титаном и, в меньшей степени, ниобием по сравнению с титанитом нефелиновых сиенитов (Иванюк и др., 2016).

Содержание $\mathrm{TiO}_{2}$ в титаните не имеет значимых связей ни с одним компонентом рядового опробования, а вот для содержания $\mathrm{Nb}_{2} \mathrm{O}_{5}$ в титаните выявлены хоть и слабые, но значимые корреляционные зависимости от содержаний $\mathrm{P}_{2} \mathrm{O}_{5}$ и $\mathrm{Al}_{2} \mathrm{O}_{\text {зобщ. }}$. породе (рис. 3).
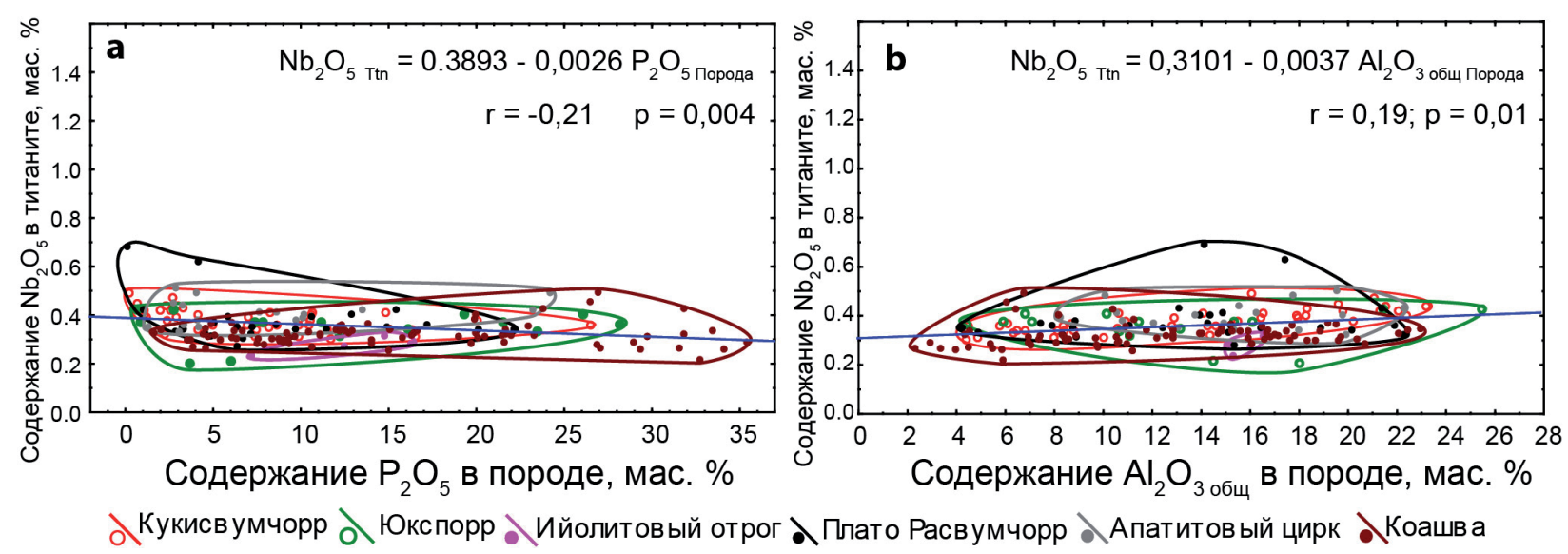

Рис. 3. Зависимость содержания $\mathrm{Nb}_{2} \mathrm{O}_{5}$ в титаните от содержания $\mathrm{P}_{2} \mathrm{O}_{5}$ (a) и $\mathrm{Al}_{2} \mathrm{O}_{\text {зобщ. }}$

(b) в породе.

Fig. 3. $\mathrm{Nb}_{2} \mathrm{O}_{5}$ concentrations in titanite $v s . \mathrm{P}_{2} \mathrm{O}_{5}$ (a) and $\mathrm{Al}_{2} \mathrm{O}_{3}$ (b) contents in the rock.

\section{Попутные компоненты в титаномагнетите}

Хибинский титаномагнетит представляет собой полную серию твёрдых растворов магнетит-ульвошпинель, обычно подвергшихся окси-экссолюционному распаду с выделением ильменита (Иванюк и др., 2006). Содержание диоксида титана в его составе варьирует в широких пределах 3-30 мас. \%, что приводит к существенному дефициту железа в хибинском титаномагнетитовом концентрате по сравнению с ковдорским и оленегорским.

Содержание $\mathrm{Fe}_{\text {обш. }}$ в магнетите имеет очень слабую, но значимую корреляционную связь с содержанием $\mathrm{Al}_{2} \mathrm{O}_{\text {зобш. }}$ в породе (рис. 4 a). Такая же слабая, но значимая связь отмечается между содержанием $\mathrm{TiO}_{2}$ в магнетите и содержанием $\mathrm{P}_{2} \mathrm{O}_{5}$ в породе (рис. 4 b). В большей степени содержание $\mathrm{TiO}_{2}$ в магнетите зависит от содержания $\mathrm{TiO}_{2}$ в породе (рис. $4 \mathrm{c}$ ).

\section{Выводы}

Полученные данные являются предварительными и отражают лишь общие закономерности изменения состава промышленно-ценных минералов. Следует отметить, что использование множественной регрессии, равно как и применение нелинейных моделей, могут существенно повысить точность расчётов (Иванов, 1987). На данном этапе при недостаточном количестве данных о составе минералов по отдельным месторождениям и разновидностям пород мы сочли использование более сложных моделей излишним. 

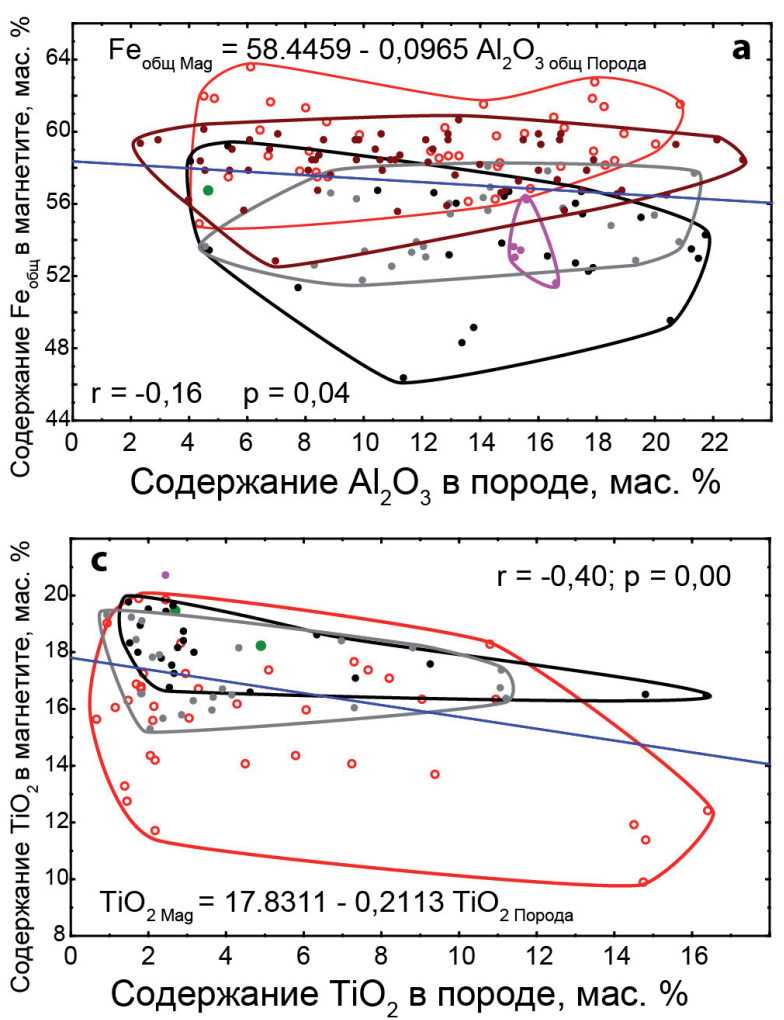

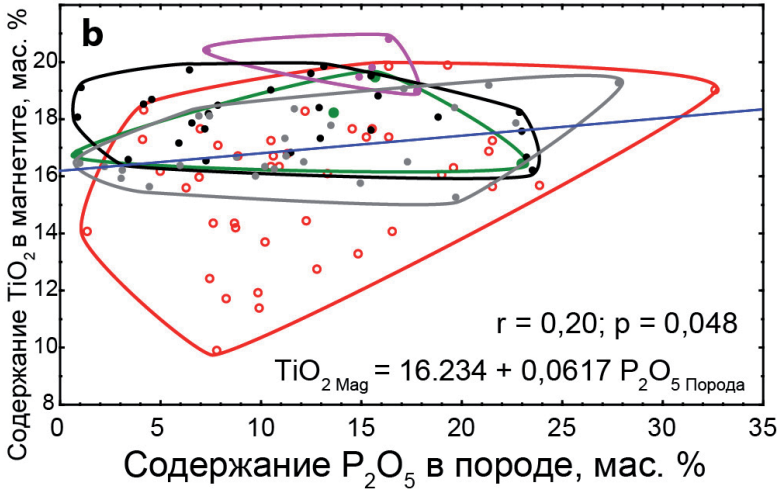

Кукисвумчорр

Юкспорр

Ийолитовый отрог

Плато Расвумчорр

Апатитов ый цирк

Коашв $а$

Рис. 4. Зависимость содержания $\mathrm{Fe}_{\text {общ. }}$ в магнетите от содержания $\mathrm{Al}_{2} \mathrm{O}_{\text {зобщ. }}$ в породе (a); содержания $\mathrm{TiO}_{2}$ в магнетите от содержания $\mathrm{P}_{2} \mathrm{O}_{5}(\mathrm{~b})$ и содержания $\mathrm{TiO}_{2}$ (c) в породе.

Fig. 4. $\mathrm{Fe}_{\text {общ. }}$ concentrations in magnetite vs. $\mathrm{Al}_{2} \mathrm{O}_{3}$ contents in the rock (a) and $\mathrm{TiO}_{2}$ concentrations in magnetite vs. $\mathrm{P}_{2} \mathrm{O}_{5}(\mathrm{~b})$ and $\mathrm{TiO}_{2}(\mathrm{c})$ contents in the rock.

Статистически значимые корреляционные связи позволяют использовать уравнения регрессии от базовых компонентов рядового опробования для оценки содержаний попутных элементов в промышленно-ценных минералах апатито-нефелиновых руд при условии создания представительных эталонных выборок по всем разновидностям пород и руд каждого из месторождений.

Исследования проводились в рамках научных тем ФИЦ КНЦ РАН 0226-2019-0051 и 02262018-0003 (Программа Президиума РАН I-48) при финансовой поддержке ОАО «Апатит».

\section{Литература}

1. Иванов С.Н. Оптимизация методики разведки и подсчёта запасов комплексных апатито-нефелиновых месторождений. Дисс. на соискание учёной степени кандидата геолого-минералогических наук. М. 1987. 259 с.

2. Иванюк Г.Ю., Горяинов П.М., Пахомовский Я.А., Коноплёва Н.Г., Яковенчук В.Н., Базай А.В., Калашников А.О. Самоорганизация рудных комплексов. М. Геокарт-Геос. 2009. 392 с.

3. Иванюк Г.Ю., Коноплева Н.Г., Пахомовский Я.А., Яковенчук В.Н., Михайлова Ю.А., Базай А.В. Титанит Хибинского щелочного массива (Кольский полуостров): новые данные // ЗРМО. 2016. № 3. С. $36-55$.

4. Иванюк Г.Ю., Пахомовский Я.А., Коноплёва Н.Г., Яковенчук В.Н., Меньшиков Ю.П., Михайлова Ю.А. Минералы группы шпинели в породах Хибинского щелочного массива (Кольский полуостров) // ЗРМО. 2006. № 5. С. 64-75.

5. Коноплева Н.Г., Иванюк Г.Ю., Пахомовский Я.А., Яковенчук В.Н., Корчак Ю.А. Типоморфизм фторапатита в Хибинском щелочном массиве (Кольский полуостров, Россия) // Записки РМО. 2013. № 3. С. $65-83$.

6. Яковенчук В.Н., Иванюк Г.Ю., Коноплева Н.Г., Корчак Ю.А., Пахомовский Я.А. Нефелин Хибинского щелочного массива (Кольский полуостров) // ЗРМО. 2010. № 2. С. 80-91. 